\title{
Cam Ambalaj Üretiminin Çevresel Sürdürülebilirliğinin Değerlendirilmesi
}

Geliş / Received: 09/05/2020

\author{
Burçin At1lgan Türkmen ${ }^{1 *}$
}

Revize / Revised: 21/07/2020

Kabul / Accepted: 21/07/2020

öZ

Sürdürülebilirlik anlayışının gittikçe önem kazanması ile hızla gelişmekte olan ambalaj sektörü üretim sektörünün sürdürülebilirliğinin arttırılabilmesi için önemli bir etken konumuna gelmiştir. Günümüzde ambalaj sektörünün çevresel sürdürülebilirliği tam olarak bilinmemektedir. Bu sebepten dolayı bu çalışmada içecek sektöründe kullanılan cam ambalajın çevresel sürdürülebilirliğinin yaşam döngüsü boyutunda analiz edilmesi amaçlanmıştır. Çalışma kapsamında içecek sektöründe kullanılan cam ambalaj için tesis inşaatı ve kurulumu, ham madde elde edilmesi ve işlenmesi, ulaşım, üretim ve tesis atık yönetimi aşamalarındaki çevresel etkiler değerlendirilmiştir. Yaşam döngüsü analizi uluslararası standartlar olan ISO 14040 ve ISO 14044 serisine göre uygulanmıştır. CML 2001 etki değerlendirme yöntemi kullanılarak on bir adet çevresel etki kategorisi değerlendirilmiştir. Çalışmamızda $1 \mathrm{~kg}$ cam şişe üretiminin küresel 1sınma potansiyeli 1,2 kg CO 2 eşdeğeri olarak hesaplanmıştır. Cam şişenin yaşam döngüsü karbon ayak izinin yaklaşık olarak \%84'ü üretim, \%7'si ham madde elde edilmesinden, \%5'i taşımacılıktan, \%3'ü tesis kurulumu ve kalan kısmının da atık yönetimi basamağından kaynaklandığı bulunmuştur. Hesaplanan çevresel etkiler incelendiğinde en fazla etkinin geldiği yaşam döngüsü basamağının enerji yoğunluğundan dolayı cam üretimi (\%4,6 ADP-\%89,0 MAETP) olduğu görülmüştür. Yapılan çevresel sürdürülebilirlik değerlendirmesi sonucunda üretim basamağından kaynaklanan emisyonların azaltılması için enerji ve ham madde girdileri ile ilgili iyileştirme çalışmalarının yapılmasının gerekliliği ortaya çıkmıştır.

Anahtar Kelimeler- Yaşam Döngüsü Analizi, Sürdürülebilirlik, Cam, Karbon Ayak İzi, Çevresel Etki

1*Sorumlu yazar iletişim: burcin.atilganturkmen@bilecik.edu.tr (https://orcid.org/0000-0003-3220-3817) Kimya Mühendisliği, Bilecik Șeyh Edebali Üniversitesi, Mühendislik Fakültesi, Bilecik, Türkiye 


\title{
Assessing the Environmental Sustainability of Glass Packaging
}

\begin{abstract}
With the increasing importance of the sustainability approach, the rapidly developing packaging sector has become an important factor for increasing the sustainability of the production sector. Today, the environmental sustainability of the packaging industry is not fully known. Therefore, this study aims to estimate the life cycle environmental impacts of glass packaging used in the beverage industry. Within the scope of the study, environmental impacts from plant construction and installation, raw material extraction and processing, transportation, production, and waste management stages were evaluated for glass packaging used in the beverage industry. Life cycle analysis has been applied according to the international standards ISO 14040 and ISO 14044. The CML 2001 method has been selected to estimate the eleven environmental impacts. The total GWP is estimated at $1.2 \mathrm{~kg} \mathrm{CO}_{2}$ equivalent per $\mathrm{kg}$ glass bottle. The production stage is the major contributor, accounting for $84 \%$ of the total GWP followed by raw materials extraction and processing (7\%), transportation (5\%), plant installation $(3 \%)$ and waste management $(1 \%)$. The results show that the life-cycle step with the most environmental impact is the glass production step $(4.6 \%$ ADP- $89.0 \%$ MAETP) due to the high energy consumption. As a result of the environmental sustainability assessment, improvements in energy and raw material inputs are required to reduce emissions from the production step.
\end{abstract}

Keywords- Life Cycle Assessment, Sustainability, Glass, Carbon Footprint, Environmental Impacts 


\section{I.GİRIS}

Toplumların çevre bilincinin arttı̆ğ günümüzde bir ürünün, üretimin ya da hizmetin maliyet ve performans gibi değerlendirme kriterlerinin yanında artık doğal kaynak kullanımı ve çevre sorunları gibi etkileri de karar verme süreçlerinde gittikçe daha sık göz önünde bulundurulan faktörler olarak karşımıza çıkmaktadır. Hayatın sağlıklı olarak devam ettirilebilmesi için, üretim sürecinde doğal kaynaklar ve ekosistem üzerindeki etkileri en aza indirmek gerekmektedir. Son zamanlarda küresel bir problem olan iklim değişikliğinden kaynaklanan endişelerden dolayı daha sürdürülebilir ürün ve üretim süreçlerine olan ilgi her geçen gün artmaktadır. Çevre dostu ürünlere talep artarken firmaların ürünlerini ve üretim süreçlerini incelemesi ve gerekli değişiklikleri yapmaları gerekmektedir. İnsanların teknoloji ile tanışması, yaşam standartlarının yükselmesi ve perakende ürünlere olan talebin artmasıyla birlikte ambalaj sanayi hızla gelişmektedir. Günümüzde ambalaj üretim, depolama, koruma, ulaştırma, dağıtım, reklam, satış ve son kullanıma kadar üretimin her aşamasında devreye girmektedir. Kısaca ambalaj yalnızca içerisine konulan ürünü koruyan bir taşıyıcı araç değil, ürünün bir parçası haline gelmiştir [1,2].

Küresel ambalaj sektörü çok geniş bir endüstri koludur. Küresel ambalaj ithalatı 2015 yılında 259 milyar \$ seviyesindeyken bu rakamın \%57'sini plastik ambalajlar, \%30'unu kağıt-karton ambalajlar, \%8'ini metal ambalajlar, \%3,5'ini cam ambalajlar ve \%1,5'ini ahşap ambalajlar oluşturmuştur. 2015 y1l küresel boyutta ambalaj ihracatı yaklaşık bir önceki yıla göre \%9 oranında azalarak 261 milyar \$ olmuştur. Ambalaj sektöründeki toplam ihracatın \%57'sini plastik ambalaj, \%30'unu kağıt-karton ambalaj oluşturmaktadır. Ülkemizde de ambalaj sektörü diğer ülkelerde olduğu gibi hızla gelişmektedir [3].

Cam silika kum, soda ve kalsit gibi maddelerin uygun şartlarda ergitilmesi ile oluşan bir takım oksitlerin meydana getirdiği sert, saydam, kimyasal dayanıklılığ yüksek ve kırılgan yapıya sahip olan amorf bir maddedir [2]. Cam ambalaj üretimi, enerji ve ham madde yoğun endüstriyel süreçlerden biridir. Ham maddelerin ergitilmesi için yüksek sıcaklık gereklidir ve bundan dolayı cam prosesinde yoğun miktarda termal enerji kullanılmaktadır. Cam üretiminde fosil yakıtların yanması sonucunda oluşan sera gazı emisyonları yoğundur. Ayrıca, cam üretimi toz, granül ve tozlu ham maddelerin kullanımını içeren bir süreçtir ve bu malzemelerin depolanması ve taşınması, toz emisyonları için önemli bir potansiyeli temsil eder [4]. Gıda ve içecek üretiminden kaynaklanan çevresel etkilerin gıda, içecek ve ambalaj malzemesinin türüne göre \%45'e kadar ambalajdan kaynaklandığ bulunmuştur [5]. Bu da ambalajın sürdürülebilirlik açısından ne kadar önemli olduğunu göstermektedir. Bu yüzden en az ham madde, doğal kaynak ve enerji kullanımı ile sürdürülebilir ambalaj üretimini sağlamak gıda ve içecek sektörü için önemli bir noktadır [6].

Sürdürülebilir ambalaj sistemlerinin sürdürülebilirliğinin değerlendirilmesi için Yaşam Döngüsü Analizi (YDA) önemli bir araçtır. Literatüre baktığımızda bu aracı kullanarak cam içecek ambalajlarının sürdürülebilirliğinin incelendiği çalışmalar bulunmuştur. Bettens and Bagard [7] raporlarında değişik cam ambalaj türlerinin çevresel etkilerini yaşam döngüsü boyutunda değerlendirmiştir. Çalışmada ham madde elde edilmesi ve işlenmesi, cam ambalaj üretimi, kullanımı ile cam ambalajın bertaraf ve geri dönüşüm basamakları incelenmiştir. Geri dönüşümsüz cam ambalaj ile \%100 geri dönüşümlü cam ambalaj için iklim değişikliğii, zehirlilik, ötrofikasyon, arazi kullanımı, enerji ve kaynak tüketimi, radyasyon gibi etki kategorileri için çevresel etki karşılaştırılması yapılmıştır. Bunlara ek olarak değişik yakıt alternatifleri için modeller oluşturulup sonuçlar karşılaştırılmıştır. Cattaneo [8] çalışmasında Kuzey Amerika'da üretilen cam ambalaj alternatiflerinin ham madde elde edilmesinden son kullanımına kadar çevresel sürdürülebilirliğini analiz etmişlerdir. Fosil yakıt tüketimi ve iklim değişikliği kategorileri için sonuçlar elde edilmiştir. Geri dönüşümün bu kategorilere etkisi de bu çalışma kapsamında değerlendirilmiştir. Çalışma sonucunda $1 \mathrm{~kg}$ cam üretimi için yaklaşı $17 \mathrm{MJ}$ fosil yakıt harcanırken $1,3 \mathrm{~kg} \mathrm{CO}_{2}$ emisyonunun açığa çıktığı bulunmuştur. Yaşam döngüsü basamakları incelendiğinde en fazla etkinin camın ergitilmesi basamağından kaynaklandığı bulunmuştur. Doublet [9] yaptığı çalışmada, polietilen teraftalat (PET) ve cam ambalaj alternatiflerinin yaşam döngüsü çevresel etkilerini karşılaş̧ırılarak değerlendirmiş̧ir. Bu çalışmada fosil yakıt kullanımı yerine yenilebilir enerji kaynakları kullanımı şeklinde değişik enerji senaryoları oluşturulmuştur. Cam şişe için şişe üretimi işlemi, ambalajın çevresel etkilerinin ortalama \%50'sine sebep olurken diğer yaşam döngüsü aşamalarından olan şişenin kapaklanması ve satış noktalarına dağıtılmasının çevresel etkilere olan katkısı sırasıyla ortalama $\% 20$ ve $\% 14$ olarak bulunmuştur. Cam şişe tekrar kullanıldığında çevresel etkilerinin \%12'sinden daha azına sahip olduğu görülmüştür. PET ambalaj için PET malzemenin üretim basamağ çevresel etkilerin \%60'ını oluşturmaktadır. İkinci en büyük çevresel etki ise \%20 ile şişenin üretim işleminden 
kaynaklanmaktadır. Bertaraf basamağı \% 7'lik etki oluşturmaktadır. Yay [10] çalışmasında ambalaj atıkları yönetiminin çevresel etkilerini yaşam döngüsü analizi yöntemi ile belirlemiştir. Bu çalı̧̧ada 3 senaryo hazırlanmıştır. İlk iki senaryoda gerçek ve yönetmeliğe uygun oranlarda geri dönüşüm yapılırken, üçüncü senaryoda herhangi bir geri dönüşüm uygulanmadan ambalaj atık depolamaya gönderilmektedir. Sonuçlar ambalaj atıklarının depolanmasının en kötü bertaraf yöntemi olduğunu göstermiş̧ir. En büyük çevresel etkinin ise su ekotoksisitesi ile ozon tabakasının incelmesi ve fosil yakıtların tüketimi kategorilerinde olduğu bulunmuştur. Falkenstein, Wellenreuther [11], içecek ambalajlarının çevresel sürdürülebilirliği konusunda genel bir model çıkartılabilmesi için bu konuda literatürde bulunan yaşam döngüsü analizi çalışmalarını değerlendirerek karşılaştırmıştır. Karşılaştırılan çalışmalarda iklim değişikliği, ozon tabakası incelmesi, ötrofikasyon, asidifikasyon, toksik emisyonlar, enerji ve su tüketimi, arazi kullanımı, zehirlilik ve geri dönüşüm oranları gibi çevresel etki göstergeleri ele alınmıştır. Analiz edilen çalışmaların sonuçlarının değişiklik gösterdiği ve bu yüzden genel bir model çıkarımının zor olduğu sonucuna varılmıştır. Planlanan model için bu sektörde daha fazla yaşam döngüsü analizi çalışmasına ihtiyaç duyulduğu belirtilmiştir. Özgen [12], ekonomik, sosyal ve çevresel sürdürülebilirliğin firma stratejisi açısından ambalaj tasarımına etkilerini araştırmıştır. Ambalaj türü olarak PET ve cam şişe incelenmiştir. Hizmet satın alma ve yaşam döngüsü maliyeti ekonomik sürdürülebilirlik için karşılaştırılmıştır. Çevresel yönden sürdürülebilirlik için ise yaşam döngüsü analizi, çevre için tasarım, entegre ürün politikaları ve ürün odaklı çevresel yönetim sistemleri incelenmiştir. Bu çalışmada sadece bazı çevresel etkiler bulunmuş olup ve herhangi bir alternatif sunumu yapılmamıştır.

Ambalaj sektörü hızla büyüyen bir sektör olmasılyla birlikte bu sektöre ait sürdürülebilirlik etkileri tam olarak bilinmemektedir. Literatürde var olan çalışmalarda genel olarak ambalaj malzemesinin geri dönüşüm sürecini inceleyen çevresel etki analizleri yapılmıştır. Bu nedenle bu çalışmada cam ambalaj malzemesinin çevresel sürdürülebilirliğinin yaşam döngüsü boyutunda analizi hedeflenmiştir. İçecek sektöründe kullanılan cam ambalaj için tesis kurulumu, ham madde elde edilmesi ve hazırlanması, ulaşım, üretim ve tesis atık yönetimi aşamalarındaki çevresel etkiler değerlendirilmiş̧ir.

\section{II.YÖNTEM}

YDA, bir ürünün, sürecin ya da hizmetin ham maddelerin elde edilmesinden başlayarak, üretim, ulaşım, kullanım ve kullanım sonrası atık yönetimini de kapsayan yaşam döngüsünün farklı aşamalarındaki çevresel etkileri inceleyen uluslararası kabul görmüş sistematik bir yöntemdir. Bütünsel yaşam döngüsünü dikkate alınarak yapılan bu analiz sonucunda değerlendirilmekte olan ürün, süreç ya da hizmetin tüm yaşam döngüsü basamaklarında ortaya çıkabilecek her tür çevresel etki değerlendirilip tüm detaylar göz önünde bulundurularak iyileştirme veya karşılaştırma olanağı sunulmaktadır [13].

Cam ambalaj için yapılan bu YDA çalışması ISO 14040 ve 14044 serisi $[14,15]$ uyarınca gerçekleştirilmiştir. Bu standart serisi, yaşam döngüsü analizi çalışmalarının gerçekleştirilmesine ve bildirilmesine yönelik genel çerçeveyi, prensipleri ve gereklilikleri belirtmektedir. Bu çalışmada YDA birbiri ile ilişkili dört adımda gerçekleştirilmiştir. İlk adım olarak çalışmanın amacı, kapsamı, sistem sınırları ve sistem için fonksiyonel birim tanımlanmıştır. Çalışmanın ikinci basamağında yaşam döngüsü envanter analizi için sisteme giren ham madde ve enerji bileşenleri ile sistemden çıkan ürün ve diğer bileşenler fonksiyonel birim ile ilişkilendirilerek hesaplanmıştır. Bundan sonraki aşamada yaşam döngüsü etki değerlendirmesi ile cam şişe üretim sürecinin tüm bileşenleri için çevresel etki kategorileri GaBi ts v9.2 [16] yazılımı kullanılarak CML 2001 yöntemi [17] ile hesaplanmış olup son aşamada ise bu sonuçlar yorumlanmıştır.

\section{A. Amaç ve Kapsam}

$\mathrm{Bu}$ çalışmanın amacı içecek sektöründe kullanılan cam ambalajın yaşam döngüsü çevresel sürdürülebilirliğinin incelenmesi ve bu ambalaj türü için potansiyel çevresel sürdürülebilirlik iyileştirme olanaklarının belirlenmesidir. Çalışmada ambalaj tipi olarak \%44 oranında geri dönüşümlü malzeme ile üretilmiş beyaz cam şişe seçilmiş̧ir. Çalışmanın fonksiyonel birimi istenilen özellikteki şekillendirilmiş ve ambalajlanmış $1 \mathrm{~kg}$ beyaz cam şişe olarak belirlenmiştir.

Çalışmanın kapsamı içerisinde cam ambalajların üretimi için tesis inşaatı ve kurulumu, ham madde elde edilmesi ve hazırlanması, nakliye, cam üretimi ve tesis içerisindeki atık yönetimi aşamaları bulunmaktadır. 
Tüketicinin ürünü kullanması basamağı ambalaj sistemleri için etki oluşturmadığından dolayı sistem sınırlarına dahil edilmemiştir. Atık yönetimi basamağı için sadece üretim tesisi dikkate alınmıştır. Cam ambalaj üretiminin yaşam döngüsü basamakları genel kapsamda Şekil 1'de gösterilmiştir. Bu çalışmada kullanılan ambalajın içine konulan içeceğin çevresel etkisi çalışmanın kapsamı dışındadır.

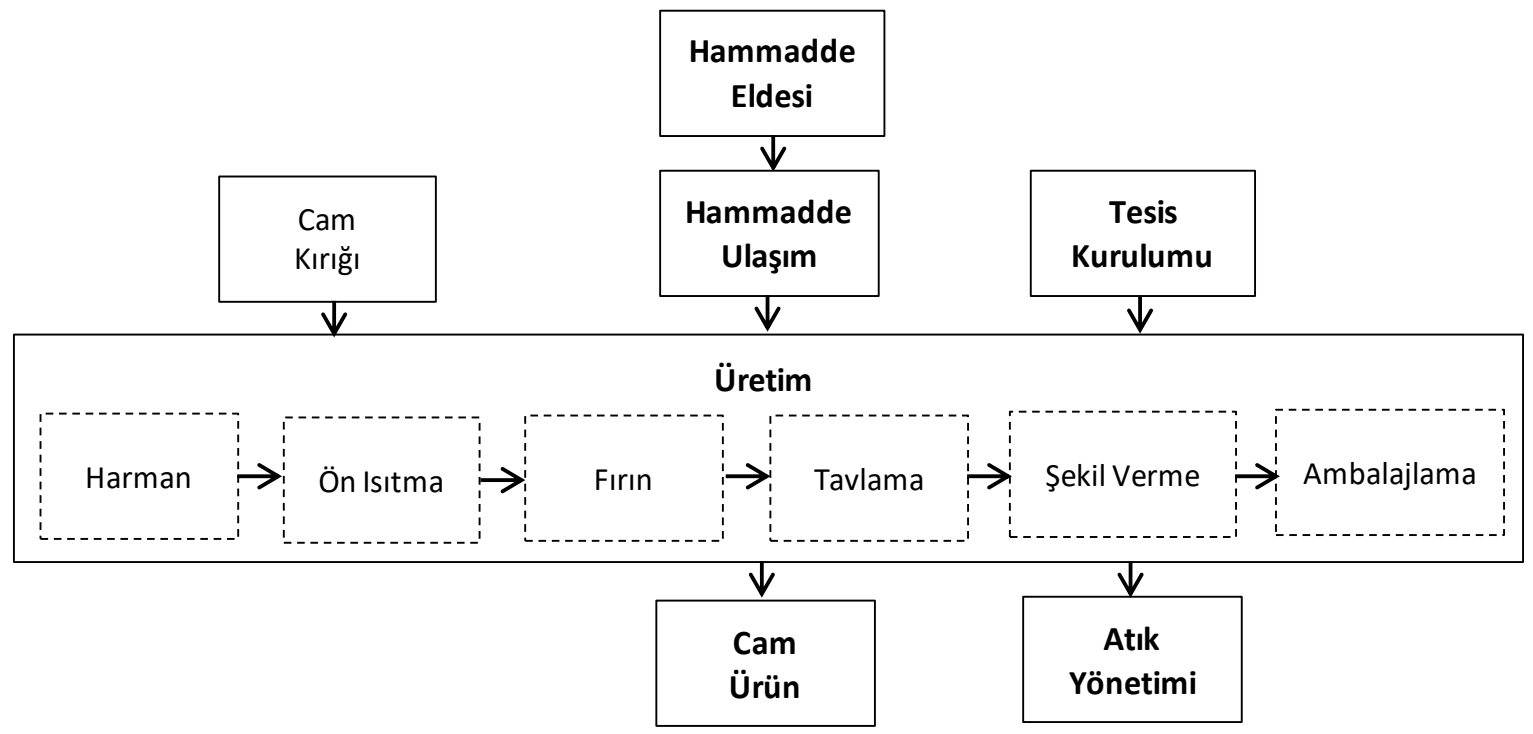

Şekil 1. Cam ambalaj sistemleri için yaşam döngüsü basamakları

Oluşturulan modeldeki ambalaj sistemleri için belirlenen yaşam döngüsü basamakları:

- Tesis kurulumu aşaması: Fabrikanın inşaatı ve fabrikada kullanılan sistemlerin kurulumu basamağıdır.

- Ham madde temini aşaması: Ham maddelerin elde edilmesi ve ham maddelere uygulanan ön işlem süreçlerini içerir.

- Ham madde nakliyesi aşaması: Her bir ham maddenin tesise nakliyesini kapsar.

- Üretim aşaması: Ham madde hazırlama (harman), ön 1sıtma, firın, tavlama, şekillendirme ve ambalajlama basamaklarından oluşmaktadır.

- Atık yönetimi aşaması: Tesis içerisinde oluşan atıklara uygulanan işlemleri içerir.

\section{B. Envanter Analizi}

Çalışmada envanter analizi veri toplama ve her bir yaşam döngüsü basamağı için girdi ve çıktı hesaplama işlemlerinden oluşmaktadır. Çalışmamızın temelini oluşturan veriler ülkemizde üretim yapmakta olan bir cam firmasından temin edilmiştir. Firmadan elde edilemeyen veriler için ise Türkiye'de cam üretimi yapmakta olan diğer firmaların sektör ve sürdürülebilirlik raporları kullanılmıştır. Söz konusu çalışmada, arka plan verileri için Ecoinvent veri tabanı [18] kullanılmıştır. Kullanılan veri tabanlarında Türkiye verisi olmadığı için seçimlerde tesisin verdiği bilgilere göre en uygun olan verilerin seçilmesine dikkat edilmiştir.

Tesis kurulumu basamağı fabrikanın inşaatı, fabrikada kullanılan cihazların ve firının kurulumunda kullanılan ham madde ve enerji tüketimi bilgilerini içerir. Veri eksikliğinden dolayı bu basamak için Hischier [19] raporunda cam ambalaj üretim tesisi için sunulan veriler kullanılmıştır.

Cam üretiminde kullanılan başlıca ham maddeler: silis kumu, soda, kalker, dolomit ve feldspattır. Cam üretiminde kullanılan en önemli ham maddeler Türkiye’de bulunduğu ve üretildiği için, cam üretimi büyük oranda yerli ham madde ile gerçekleştirilmektedir. Cam üretimi yapan fabrikanın Bilecik il sınırları içerisinde olduğu varsayılmıştır. Bu varsayıma bağlı olarak ulaşım verileri Tablo 1'de gösterilmiştir. 
Tablo 1. Çalışmada kullanılan ulaşım verileri

\begin{tabular}{llllll}
\hline Ham madde & Şehir/Ülke & $\begin{array}{l}\text { Kara yolu } \\
(\mathbf{k m})\end{array}$ & Şehir/Ülke & $\begin{array}{l}\text { Kara yolu } \\
(\mathbf{k m})\end{array}$ & $\begin{array}{l}\text { Deniz yolu } \\
(\mathbf{k m})\end{array}$ \\
\hline Silis Kumu & Bilecik/Türkiye & 40 & Kahire/ Mısır & 750 & 640 \\
Soda & Mersin/Türkiye & 785 & - & - & - \\
Feldspat & Bilecik/Türkiye & 40 & - & - & - \\
Dolomit & Bilecik/Türkiye & 40 & - & - & - \\
Kalker & Bilecik/Türkiye & 40 & Kırklareli/Türkiye & 300 & - \\
Cam Kırığı & Bilecik/Türkiye & 100 & - & - & - \\
Ambalaj & Kocaeli/Türkiye & 150 & - & - & \\
\hline
\end{tabular}

Çalışmamızda cam kırıklarının fabrika dışından ve fabrika içinden sağlanarak belirli oranda tekrar üretime girdiği yani camın geri dönüştürüldüğü varsayımı yapılmıştır. Bu çalışma için seçilen cam \% 44 oranında cam kırı̆̆ı içermektedir. Tablo $2^{\prime}$ de yaşam döngüsü modellemesinde kullanılan ham maddeler ve miktarları verilmiştir. Tesise getirilen ham maddeler silolarda depolanıp harman hazırlama kısmında camın türüne göre belirlenen reçeteye uygun olarak karıştırılır. Karıştırma işlemi karıştırıcı içindeki bıçaklar yardımıyla yapılır. Hazırlanan harman konveyör bantlarla fırına taşınır. Taşıma işlemi sırasında cam kırığı da istenilen miktarda harmana ilave edilir.

Tablo 2. Çalışmada kullanılan ham madde verileri

\begin{tabular}{ll}
\hline Ham madde & Miktar $(\mathbf{k g})$ \\
\hline Silis Kumu & 0,35 \\
Soda & 0,11 \\
Feldspat & 0,04 \\
Dolomit & 0,02 \\
Kalker & 0,11 \\
Cam Kırığı & 0,50 \\
\hline
\end{tabular}

Hazırlanan harman $1550-1650{ }^{\circ} \mathrm{C}$ 'ye kadar çıkarılarak eriyik cam elde edilir. Cam ergitme yüksek sıcaklıklara dayanıklı firınlarda yapılmaktadır. Türkiye’deki orta ya da büyük işletmelerde firınları 1sıtmak için doğalgaz kullanılmaktadır. Homojen sıcaklığa ulaşan eriyik camın verimli bir şekilde şekillendirilmesi için uygun olan sıcaklık değerine $\left(500{ }^{\circ} \mathrm{C}\right.$ civarı) soğutulması gereklidir. Bu işlem sonucunda stabil ve homojen dağılmış ve istenilen sıcaklığa ulaşmış eriyik cam elde edilmiş olur. Erimiş haldeki karışım, şekillendirme kısmına verilir. Cam şişenin şekillendirilmesi makine ile yapılmaktadır. Şekillendirilen cam yeniden ısıtılıp çevre sıcaklığına kadar soğutularak iç gerilmeler yok edilir ve cam daha dayanıklı hale gelir. Soğutma ünitesi toplama bandından çıkan ürünler cam üretiminin son basamağı olan paketleme kısmına gelmektedir [4]. Cam şişenin ambalajlanması için polietilen, karton ve ahşap palet kullanılmıştır [19]. 
Oluşturulan yaşam döngüsü modelinde Türkiye şebeke elektriği kullanılmıştır. 2018 yılı temel alınarak Türkiye şebeke elektriğinden gelen yaşam döngüsü boyutundaki çevresel etkiler daha önce yapılan çalışma [20] temel alınarak Türkiye elektrik üretim istatistikler [21] kullanılarak hesaplanmıştır. Doğalgaz verileri de Türkiye için yayınlanan doğalgaz raporundan [22] elde edilen veriler temel alınarak modellenmiştir. Tablo 3 'te yaşam döngüsü modellemesinde kullanılan enerji verileri sunulmuştur.

Tablo 3. Çalışmada kullanılan enerji verileri

\begin{tabular}{cc}
\hline Enerji türü & $\begin{array}{c}\text { Kullanılan enerji miktarı } \\
\text { (MJ/fonksiyonel birim) }\end{array}$ \\
\hline Elektrik & 0,92 \\
Doğalgaz & 3,75 \\
\hline
\end{tabular}

Atık yönetimi cam ambalajın üretimi sırasında oluşan atık suyun arıtılması ve katı atığın geri dönüştürülmesi veya bertaraf edilmesi basamaklarını içermektedir. Üretim sırasında oluşan atık suyun, tesis içerisinde bulunan atık su arıtım tesisinde arıtıldığı varsayılmıştır. Ham madde atıkları, atık yağlar ve ambalaj malzemeleri gibi katı atıkların $\% 50$ oranında geri dönüştürülürken $\% 50$ oranında bertaraf edildiği varsayılmıştır [19].

\section{III.BULGULAR VE TARTIȘMA}

Yapılan çalışmada GaBi ts v9.2 [16] yazılımı kullanılarak cam şişe için yaşam döngüsü modellemesi yapılmıştır. Elde edilen sonuçlar detaylı olarak açıklanarak benzer çalışmalardan elde edilen sonuçlarla karşılaştırılmıştır.

\section{A. Etki Analizi}

Etki analizi basamağında cam üretim YDA çalışmasının çevresel etki sonuçları CML 2001 metodu [17] ile hesaplanmıștır. Çalışmada 11 adet çevresel etki kategorisi değerlendirilmiștir: abiyotik kaynakların tükenmesi fosil olmayan (ADP), abiyotik kaynakların tükenmesi fosil (ADP fosil), asidifikasyon potansiyeli (AP), ötrofikasyon potansiyeli (EP), tatlı su ekotoksisitesi potansiyeli (FAETP), küresel 1sınma potansiyeli (GWP), insan toksisitesi potansiyeli (HTP), deniz suyu ekotoksisitesi potansiyeli (MAETP), ozon tabakası tükenmesi potansiyeli (ODP), fotokimyasal ozon oluşturma potansiyeli (POCP), kara ekotoksisitesi potansiyeli (TETP).

Yapılan çalışmada hesaplanan çevresel etki kategorileri, yaşam döngüsü analizi sonuçlarının daha kolay anlaşlabilmesi için oluşturulan modelde tesis kurulumu, ham madde temini, ham madde nakliyesi, cam üretim ve tesis atık yönetimi basamaklarını içine alan cam ambalaj üretimi toplam çevresel etki değerleri sunulmuştur.

Elde edilen sonuçlar Şekil 2'de verilmiștir. Cam ambalaj için tesis kurulumu, ham maddelerin elde ve işlenmesi, ham madde ulaşımı, cam ambalaj üretimi ve tesis atık yönetimi aşamalarında açığa çıkan çevresel etkiler Şekil 3'te gösterilmiş̧ir. Çalışma kapsamında cam içecek ambalaj için hesaplanan her bir çevresel etki kategorisi ve bu çevresel etkilerin kaynağı olan yaşam döngüsü basamakları aşağıda detaylı olarak açıklanmışıtır. 


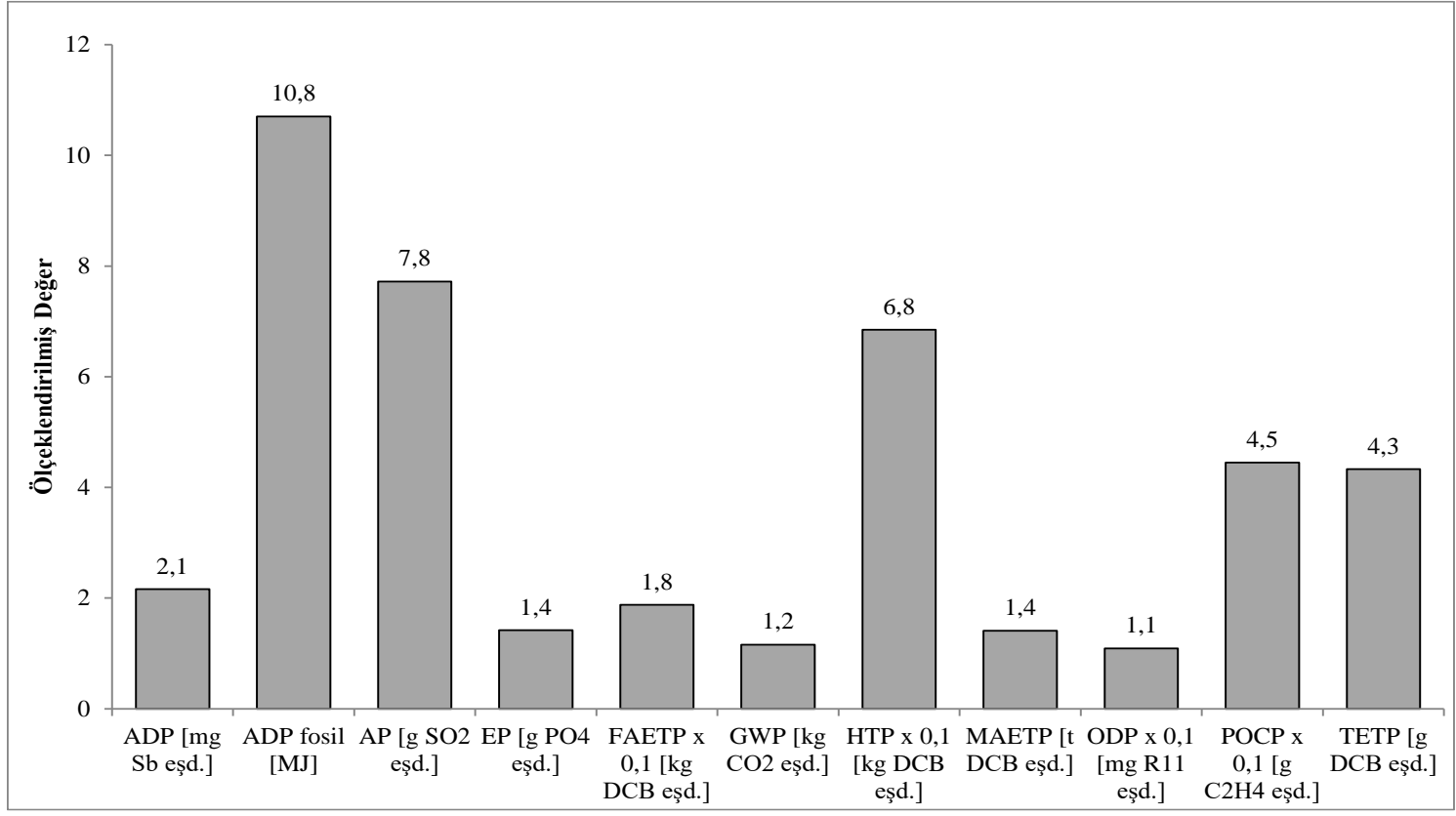

Şekil 2.Cam şişe için yaşam döngüsü çevresel etkiler

(Etkiler ölçeklendirilmiştir ve çalıșmanın fonksiyonel birimine göre hesaplanmıștır. ADP: Abiyotik kaynakların tükenmesi fosil olmayan, ADP fosil: Abiyotik kaynakların tükenmesi fosil, AP: Asidifikasyon potansiyeli, EP: Ötrofikasyon potansiyeli, FAETP: Tatlı su ekotoksisitesi potansiyeli, GWP: Küresel 1sınma potansiyeli, HTP: İnsan toksisitesi potansiyeli, MAETP: Deniz suyu ekotoksisitesi potansiyeli, ODP: Ozon tabakası tükenmesi potansiyeli, POCP: Fotokimyasal ozon olușturma potansiyeli, TETP: Kara ekotoksisitesi potansiyeli)

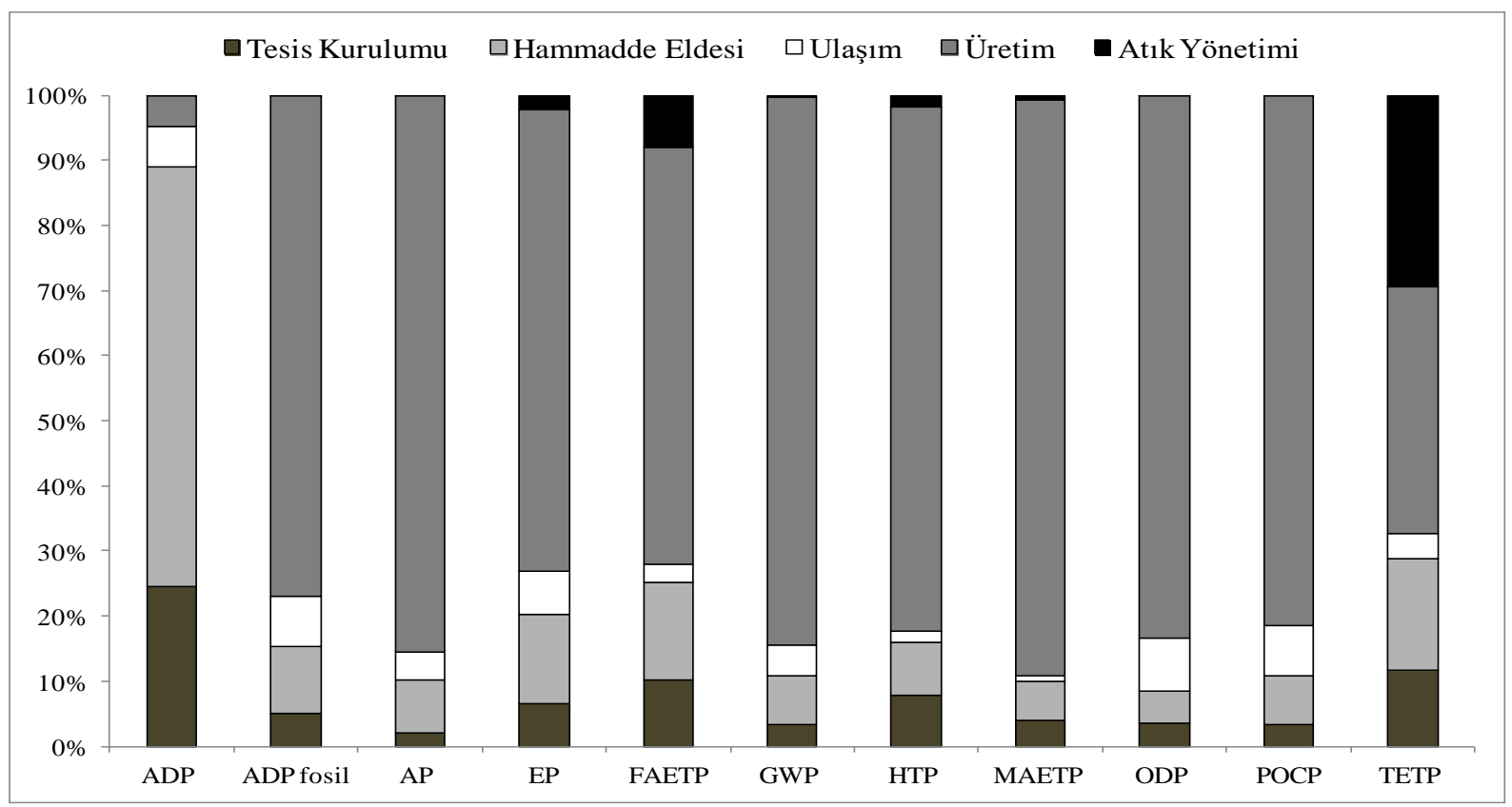

Şekil 3.Cam şișe için karbon ayak izinin yaşam döngüsü basamaklarına göre dağılımı

1) Abiyotik Kaynakların Tükenmesi Potansiyeli (ADP): Abiyotik kaynakların tükenmesi potansiyeli antimon ( $\mathrm{Sb}$ ) eşdeğeri (eşd.) olarak ifade edilir ve sistemin yaşam döngüsü boyunca sebep olduğu doğal ham madde tüketimi sonucunu verir. Belirlenen özellikteki $1 \mathrm{~kg}$ 'lık cam şişe elde edilmesi toplam 2,1 mg Sb eşd. etkiye 
sebep olmaktadır. Şekil 3'te görüldüğü gibi cam şişe yaşam döngüsünde ham madde elde edilmesi ve işlenmesi prosesi (\%64) abiyotik kaynakların tükenmesine en çok etki eden basamaktır. Bunu \%25'lik pay ile tesis kurulumu basamağı takip etmektedir.

2) Abiyotik Kaynakların Tükenmesi Potansiyeli Fosil (ADP fosil): Bu etki kategorisi yaşam döngüsü basamakları tarafından kullanılan fosil yakıtların etkisini ifade eder ve MJ referans birimi ile verilir. Şekil 2'de gösterildiği gibi cam şişe üretiminin toplam abiyotik kaynakların tükenmesi potansiyeli 10,8 MJ/kg cam şişe olarak bulunmuştur. Yaşam döngüsü basamakları tarafından tüketilen doğal gazın abiyotik kaynak tüketimine etkisi \%60 olarak belirlenmiştir. Bunu ham petrol (\%18), taş kömürü (\%12) ve linyit (\%10) takip etmektedir.

3) Asidifikasyon Potansiyeli (AP):Asidifikasyon potansiyeli sülfür dioksit $\left(\mathrm{SO}_{2}\right)$, amonyak $\left(\mathrm{NH}_{3}\right)$, azot oksitler (NOx) gibi asitli gazların atmosferdeki su ile etkileşime girmesi sonucu asit yağmurları oluşturması potansiyelidir ve $\mathrm{SO}_{2}$ eşd. olarak ifade edilir. Toplam asidifikasyon potansiyeli 7,8 g SO $\mathrm{SO}_{2}$ eşd./kg cam şişe olarak bulunmuştur (Şekil 2). Bu çevresel etki kategorisine sırasıyla $\mathrm{SO}_{2}$ (\%73) ve azot monoksit (NO) (\%23) neden olmaktadır. Üretim prosesi, bu etkinin toplam \%85'lik kısmını oluşturmaktadır. Bunu \%8'lik pay ile ham madde elde edilmesi ve işlemesi basamağı takip etmektedir.

4) Ötrofikasyon Potansiyeli (EP): Ötrofikasyon, canlılara zarar veren, ekosistemde hızlı biyokütle artışına yol açan bir kimyasal besin konsantrasyonunun birikmesidir. Bu etki kategorisi fosfat $\left(\mathrm{PO}_{4}\right)$ eşd. olarak ifade edilir. Cam şişe üretiminde $1 \mathrm{~kg}$ 'lık ürün için $1,4 \mathrm{~g} \mathrm{PO}_{4}$ eşd. olarak hesaplanan toplam ötrofikasyon değerinin Şekil 3'te gösterildiği gibi \%71'lik kısmı cam üretim prosesinden kaynaklanmaktadır. Ham madde elde edilmesi ve işlenmesi, ham madde ulaşımı ve tesis kurulumunun ötrofikasyon etkisi üzerindeki payları sırasıyla \%13, \%7 ve $\% 6$ 'dir.

5) Tatlı Su Ekotoksisitesi Potansiyeli (FAETP): Bu çevresel etki kullanılan kimyasalların nehirler ve göller gibi tatlı su kaynaklarındaki ekosisteme verdikleri zararı ölçmektedir ve 1,4-diklorobenzen (DCB) eşd. olarak ifade edilmektedir. Cam şişe yaşam döngüsünde bu etki Şekil 2'de belirtildiği gibi toplam 0,2 kg DCB eşd./kg cam şişe olarak bulunmuştur. Bu etkinin \%65'i cam üretimi, \%15'i ham madde elde edilmesi ve işlenmesi, \%10'u tesis kurulumu ve \%8'i atık yönetimi basamağından kaynaklanmaktadır (Şekil 3).

6) Küresel Isınma Potansiyel (GWP): Küresel ısınma potansiyeli, sera gazlarının oluşturduğu sera etkisinden kaynaklanan sıcaklıktaki değişim olarak tanımlanabilir. Bu etki karbondioksit $\left(\mathrm{CO}_{2}\right)$ eşd. olarak ifade edilir. Çalışmamızda cam üretim prosesinden kaynaklanan toplam GWP $1,2 \mathrm{~kg} \mathrm{CO} 2$ eşd./kg cam şişe olarak bulunmuştur. $\mathrm{Bu}$ etkiye $\% 93$ oranında $\mathrm{CO}_{2}$ emisyonları ve \%6 oranında metan $\left(\mathrm{CH}_{4}\right)$ emisyonları sebep olmaktadır. Şekil 3 'te gösterildiği gibi küresel ısınma potansiyeline \%84'lük değer ile cam ambalaj üretim prosesi en büyük paya sahibidir. Üretim basamakları içerisinde en büyük etki, tüm yaşam döngüsü basamaklarında kullanılan toplam enerjinin yaklaşık \%80’lik kısmının kullanıldığı firın basamağından kaynaklanmaktadır.

7) Insan Toksisitesi Potansiyeli (HTP): Bu etki kategorisi çevreye salınan birçok kimyasalın, özellikle ağır metallerin, yüksek konsantrasyonlarda havaya ve suya salınmasının insanlar üzerindeki toksik etkisinin potansiyelidir ve DCB eşd. olarak ifade edilir. $1 \mathrm{~kg}$ 'lık cam şişe üretiminin toplam insan toksisitesi potansiyeli 0,7 kg DCB eşd. olarak bulunmuştur. Şekil 3'te gösterildiği gibi cam üretimi basamağ $\% 81$ ile bu etkiye en büyük katkıda bulunurken, ham madde elde edilmesi (\%8) ve ulaşımı (\%8) bu çevresel etki kategorisine aynı oranda etki etmektedir.

8) Deniz Suyu Ekotoksisitesi Potansiyeli (MAETP): Deniz suyu ekotoksisitesi potansiyeli salınan kimyasalların deniz ve okyanus ekosistemlerine verdiği zararı ölçmektedir. Bu etki kategorisi DCB eşd. olarak verilmektedir. Toplam MAETP değeri 1,4 t DCB eşd./kg cam şişe olarak hesaplanmıştır (Şekil 2). Cam üretimi, \%81 ile deniz sularına olan toksisiteye en fazla etki eden yaşam döngüsü basamağı olarak bulunmuştur. Üretim proseslerinden en fazla etki camın ergitildiği fırınlama basamağından gelmektedir. Deniz sularına olan bu toksik etki başlıca suya berilyum (Be) salınımından kaynaklanmaktadır.

9) Ozon Tabakasının Tükenmesi Potansiyeli (ODP): Bu etki kategorisi kloroflorokarbonlar gibi bazı kimyasalların Güneş’in zararlı ışınlarından koruma özelliği olan ozon tabakasına zarar verme potansiyelini değerlendirir. Ozon tabakasının tükenme potansiyeli trikloroflorometan (R11) eşd. olarak ifade edilmektedir. Cam şişe üretimi için toplam $0,1 \mathrm{mg}$ R11 eşd./kg cam şişe olarak hesaplanmıştır. Bu etkinin büyük bir kısmı (\%83) 
enerji yoğun bir süreç olan cam üretim basamağından kaynaklanmaktadır (Şekil 3). Doğalgazın taşınması sırasında soğutucu gaz kullanılmasından dolayı ortaya çıkan halojenli gazların ODP üzerinde büyük etkisi vardır.

10) Fotokimyasal Ozon Oluşturma Potansiyeli (POCP): POCP insan sağlığına ve ekosisteme zarar veren reaktif maddelerin (özellikle ozon) oluşumu potansiyelidir. Bu etki kategorisi etilen $\left(\mathrm{C}_{2} \mathrm{H}_{4}\right)$ eşd. olarak ifade edilmektedir. Şekil 2 ve Şekil 3 'te gösterildiği gibi cam şişe üretimi için hesaplanan toplam $0,45 \mathrm{~g} \mathrm{C}_{2} \mathrm{H}_{4}$ eşd. olan bu etkinin \%81'lik kısmı cam üretimi basamağından gelirken bunu ham madde elde edilmesi ve hazırlanması (\%8) ve ham madde ulaşımı (\%7) basamakları takip etmektedir. Cam 1sıtma ve ergitme prosesleri sırasında havaya salınan $\mathrm{SO}_{2}(\% 51)$ ve $\mathrm{NOx}(\% 22)$ cam şişe üretiminde bu etkiye sebep olan başlıca emisyonlardır.

11) Kara Ekotoksisitesi Potansiyeli (TETP): Kara ekotoksisitesi potansiyeli kimyasal salınımı sonucunda kara ekosistemleri ve karasal organizmalar üzerindeki toksik etki potansiyelidir. Bu çevresel etki kategorisi DCB eşd. olarak verilmektedir. Cam üretim sürecinin yaşam döngüsü boyutunda toplam TETP değeri 4,3 g DCB eşd./kg cam olarak bulunmuştur (Şekil 2). Cam üretimi (\%38) kara ekotoksisite etki kategorisine en fazla etki eden yaşam döngüsü basamağı olarak bulunmuştur. Bunu atık yönetimi (\%29), ham madde elde edilmesi (\%17) ve tesis kurulumu (\%12) basamakları takip etmektedir. Üretim proseslerinden en fazla etki camın ergitildiği firın basamağından gelmektedir.

\section{B. Sonuçların Karşılaştırılması}

Literatürde düz cam, ambalaj camı ve borlu cam gibi farklı cam türleri için yaşam döngüsü analizi çevresel etki çalışmaları mevcuttur [7-9, 23-31]. Literatürde bulunan bu çalışmalarda genel olarak farklı fonksiyonel birim kullanılmıştır. Çalışmamızda fonksiyonel birim $1 \mathrm{~kg}$ bitmiş cam şişe üretimi olarak alınmıştır.

Bu çalışmadan elde edilen sonuçlar ambalaj üretimi için kullanılan aynı sistem sınırları ve benzer fonksiyonel birim için çalışan ve CML 2001 etki kategorisini kullanan çalışmaların sonuçlarıyla karşılaştırılmıştır ve sonuçların genel olarak bu çalışmalardaki sonuçlarla elde edilen aralıkta olduğu görülmüştür. Örnek olarak 1 $\mathrm{kg}$ cam şişe üretimi için küresel isınma potansiyeli en düşük $0,5 \mathrm{~kg} \mathrm{CO}$ eşd. [19] ve en yüksek $1,3 \mathrm{~kg} \mathrm{CO}_{2}$ eşd. [8] olarak literatürde bulunmuştur. Bizim bu çevresel etki kategorisi için bulduğumuz değer $1,2 \mathrm{~kg} \mathrm{CO}_{2} \mathrm{eşd} . / 1 \mathrm{~kg}$ cam şişedir ve literatürden elde edilen aralık içerisindedir. Sonuçlardaki farklılık değişik ham madde türü ve miktarı, farklı geri dönüşüm oranı ve ülkelere göre değişen enerji verilerinden kaynaklanmaktadır.

\section{IV.SONUÇLAR}

Ambalaj malzemelerinin tüketimi küresel boyutta hızla artmaktadır. Ambalaj malzemeleri hemen hemen tüm faaliyet alanlarında kullanılırken birçok endüstri kolu için ise temel ihtiyaç haline gelmiştir. Bu nedenle, ambalaj malzemelerinin yaşam döngüsü boyunca çevresel etkilerini değerlendirmek ve çevre üzerindeki zararlı etkilerini önemli ölçüde azaltmak üretim sektörünün sürdürülebilirliği için çok önemlidir.

Yapılan bu çalışma kapsamında içecek sektöründe kullanılan cam ambalaj için fabrika kurulumu, ham madde elde edilmesi ve işlenmesi, ulaşım, üretim ve atık aşamalarında oluşan yani yaşam döngüsündeki çevresel etkiler değerlendirilmiştir. Yaşam döngüsü analizi uluslararası standartlar olan ISO 14040 ve ISO 14044 serisi standartlarına göre uygulanmıştır. CML 2001 etki değerlendirme yöntemi kullanılarak on bir adet çevresel etki kategorisi hesaplanmıştır.

Çalışmamızda $1 \mathrm{~kg}$ cam şişe üretiminin küresel ısınma potansiyeli 1,2 $\mathrm{kg} \mathrm{CO}_{2}$ eşd. olarak bulunmuştur. Cam şişenin yaşam döngüsü karbon ayak izlerinin yaklaşık olarak \%84'ü üretim, \%7’i ham madde elde edilmesinden, \%5'i taşımacılıktan, \%3'ü tesis kurulumu ve kalan kısmının da tesis atık yönetimi basamağından kaynaklandığı sonucuna ulaşılmıştır. Hesaplanan çevresel etkiler incelendiğinde en fazla etkinin geldiği yaşam döngüsü basamağının enerji yoğunluğundan dolayı genellikle cam üretimi basamağı (ADP için \%4,6-MAETP için \%89,0) olduğu görülmüştür.

Çalışmadan elde edilen sonuçlara göre cam ergitme prosesi için enerji verimliliği çalışması yapılması çevresel etkilerde büyük oranda azalma sağlayacaktır. Bunun yanı sıra yenilenebilir enerji tüketiminin teşvik edilmesi de sürdürülebilir cam ambalaj üretimi açısından önem arz etmektedir. Ayrıca cam üretim prosesi ham 
madde yoğun bir prosestir. Harman içerisindeki atık cam oranının arttırılması ile çevresel etkilerde iyileştirme sağlanabilir.

\section{TEŞEKKÜR}

Bu çalışma, Bilecik Şeyh Edebali Üniversitesi Bilimsel Araştırma Projeleri Koordinasyon Birimi (Proje: 2017-02.BŞEÜ.03-04) tarafından desteklenmiş̧ir.

\section{KAYNAKLAR}

[1] Üçüncü, M., Gıdaların Ambalajlanması. 2000, İzmir: Ege Üniversitesi Basımevi.

[2] Bansal, N.P. and R.H. Doremus, Handbook of Glass Properties. 2013: Elsevier.

[3] PAGEV, Türkiye Plastik Ambalaj Malzemeleri Sektör Raporu, Türk Plastik Sanayicileri Araştırma, Geliştirme ve Eğitim Vakfı, 2016.

[4] Scalet, B.M et. all, Best Available Techniques (BAT)Reference Document for the Manufacture of Glass, Industrial Emissions Directive 2010/75/EU, JRC Reference Report; European Union. 2013, Luxembourg.

[5] Simon, B., M.B. Amor, and R. Földényi, Life cycle impact assessment of beverage packaging systems: Focus on the collection of post-consumer bottles. Journal of Cleaner Production, 2016. 112 (Part 1): p. 238-248.

[6] UNILEVER, Sustainable Packaging? 2009, The Netherlands.

[7] Bettens, F. and R. Bagard, Life Cycle Assessment of Container Glass in Europe. European Container Glass Federation, 2016.

[8] Cattaneo, J.J., Environmental Overview. Complete Life Cycle Assessment of North American Container Glass, 2010.

[9] Doublet, G., LCA of Rivella and Michel soft drinks packaging. Institute of Environmental Engineering (IFU), Chair of Ecological System Design (ESD). 2012, Zürich.

[10] Yay, A.S.E., Yaşam döngüsü analizinin ambalaj atıklarının yönetiminde kullanılması. Sakarya University Journal of Science, 2017. 21(5): p. 1008-1017.

[11] Falkenstein, E.v., F. Wellenreuther, and A. Detzel, LCA studies comparing beverage cartons and alternative packaging: Can overall conclusions be drawn? The International Journal of Life Cycle Assessment, 2010. 15(9): p. 938-945.

[12] Özgen, C., Sürdürülebilirlik Kavramının Firma Stratejisi Açısından Ambalaj Tasarımına Etkilerinin Irdelenmesi. Doktora Tezi, İTÜ Fen Bilimleri Enstitüsü. 2013, İstanbul.

[13] Baumann, H. and A.M. Tillman, The Hitch hiker's Guide to LCA - An orientation in life cycle assessment methodology and application. 2004.

[14] ISO, ISO 14044: Environmental Management - Life cycle assessment - Requirements and guidelines. 2006, Geneva, Switzerland.

[15] ISO, ISO 14040: Environmental management - Life cycle assessment - Principles and framework. 2006, Geneva, Switzerland.

[16] Sphera, GaBi LCA Software and Database, Sphera. 2020, Stuttgart, Echterdingen.

[17] CML. CML-IA Characterisation Factors. [November 2010]; Available from http://cml.leiden.edu/software/data-cmlia.html. 
[18] Ecoinvent, Ecoinvent Database v2.2. Swiss Centre for Life Cycle Inventories. 2010, St Gallen, Switzerland.

[19] Hischier, R., Life Cycle Inventories of Packaging and Graphical Paper. Final report Ecoinvent data v2.0 No. 11: Swiss Centre for Life Cycle Inventories, EMPA - TSL. 2007, Dübendorf.

[20] Atilgan, B. and A. Azapagic, Assessing the Environmental Sustainability of Electricity Generation in Turkey on a Life Cycle Basis. Energies, 2016. 9(1): p. 31.

[21] TEIAS. Electricity Generation and Transmission Statistics of Turkey. 2019; Available from http://www.teias.gov.tr/TurkiyeElektrikIstatistikleri.aspx.

[22] BOTAS, Natural Gas / Crude Oil Report. Petroleum Pipeline Corporation. 2019, Ankara.

[23] Mata, T.M. and C.A.V. Costa, Life cycle assessment of different reuse percentages for glass beer bottles. The International Journal of Life Cycle Assessment, 2001. 6(5): p. 307-319.

[24] Rajat, N., Life cycle assessment on the aluminium can and glass bottle for packaging of $500 \mathrm{ml}$ beer in UCD School of Biosystems and Food Engineering. University College Dublin. 2016, Dublin, Ireland.

[25] Vinci, G., et al., A sustainable innovation in the Italian glass production: LCA and Eco-Care matrix evaluation. Journal of Cleaner Production, 2019. 223: p. 587-595.

[26] Usbeck, V.C., J. Pflieger, and T. Sun, Life Cycle Assessment of Float Glass, in Glass for Europe. 2011: P. International.

[27] AIGMF, Life Cycle Assessment of "Container Glass and Comparison with Alternate Packaging Mediums (PET, Beverage Carton, Aluminum Can and Pouch)" The All India Glass Manufacturers' Federation (AIGMF), 2016: New Delhi.

[28] Glass Fibre Europe, Life cycle assessment of CFGF - Continuous Filament Glass Fibre Products, 2016.

[29] Humbert, S., et al., Life cycle assessment of two baby food packaging alternatives: glass jars vs. plastic pots. 2009. 14(2): p. 95-106.

[30] Accorsi, R., L. Versari, and R.J.S. Manzini, Glass vs. plastic: Life cycle assessment of extra-virgin olive oil bottles across global supply chains. 2015. 7(3): p. 2818-2840.

[31] Larsen, A.W., H. Merrild, and T.H. Christensen, Recycling of glass: accounting of greenhouse gases and global warming contributions. Waste Management \& Research: The Journal of the International Solid Wastes and Public Cleansing Association, ISWA, 2009. 27(8): p. 754-762. 